\title{
P02.163. Acupuncture and donor egg in vitro fertilization cycles: a retrospective chart review comparing two acupuncture protocols
}

\author{
L Hullender Rubin $^{1 *}$, M Opsahll$^{2}$, D Ackerman ${ }^{1}$ \\ From International Research Congress on Integrative Medicine and Health 2012 \\ Portland, Oregon, USA. 15-18 May 2012
}

\section{Purpose}

Research investigating the effect of acupuncture on in vitro fertilization (IVF) pregnancy outcomes has focused primarily on non-donor cycles. Most trials excluded donor IVF cycles in their design, as donor IVF live birth outcomes are higher than non-donor IVF. In this retrospective chart review, we compared the effect of two standardized acupuncture protocols on donor IVF live birth outcomes.

\section{Methods}

Live births were compared between patients who elected acupuncture treatment before and after embryo transfer (ET) to those who did not. Acupuncture was performed at a private infertility clinic the same day as ET by one of seven licensed acupuncturists. One hundred thirty-four patients had an embryo transfer, of which 43 elected acupuncture. The acupuncture group " $\mathrm{A}$ " (Acu A) received the Craig protocol (Paulus protocol plus CV-6/Qihai before and KI-3/Taixi after ET) from 2005-2007 $(\mathrm{N}=23)$. From 2008-2009, the acupuncture group "B" (Acu B) received the Paulus protocol modified only with $\mathrm{CV}-6$ / Qihai added pre-ET $(\mathrm{N}=20)$. Live birth outcomes were analyzed using crude risk ratios.

\section{Results}

There were 20 (87\%) live births in the Acu A Group and 31 (66\%) in the No Acu A group ( $R R=1.32,95 \%$ CI $1.02-$ $1.71, \mathrm{p}=0.04)$. After removing KI-3/Taixi from the acupuncture protocol, there were $10(50 \%)$ live births in the Acu B group and 28 (64\%) in the No Acu B group ( $\mathrm{RR}=1.37,95 \% \mathrm{CI} 0.76-2.47, \mathrm{p}=0.29)$. When comparing

${ }^{1}$ Oregon College of Oriental Medicine, Research Department, Portland, USA Full list of author information is available at the end of the article
Acu A to Acu B, there were significantly more live births in the Acu A group ( $R R=1.74,95 \%$ CI $1.09-2.77, \mathrm{p}=0.02)$.

\section{Conclusion}

Donor IVF live births may be improved with the Craig acupuncture protocol. This finding should be taken cautiously as more rigorous research including randomization and a larger sample size is needed.

\section{Author details}

'Oregon College of Oriental Medicine, Research Department, Portland, USA.

${ }^{2}$ Northwest Center for Reproductive Medicine, Kirkland, USA.

Published: 12 June 2012

doi:10.1186/1472-6882-12-S1-P219

Cite this article as: Rubin et al:: P02.163. Acupuncture and donor egg in vitro fertilization cycles: a retrospective chart review comparing two acupuncture protocols. BMC Complementary and Alternative Medicine 2012 12(Suppl 1):P219.

Submit your next manuscript to BioMed Central and take full advantage of:

- Convenient online submission

- Thorough peer review

- No space constraints or color figure charges

- Immediate publication on acceptance

- Inclusion in PubMed, CAS, Scopus and Google Scholar

- Research which is freely available for redistribution 